\title{
CIBERCARTOGRAFIA o novo paradigma da cartografia ainda ausente das aulas de Geografia
}

\author{
Vânia Lúcia Costa Alves Souza ${ }^{1}$
}

\begin{abstract}
Resumo: A evolução da cibernética ocorre em diferentes etapas e geram novos conhecimentos que influenciam as outras ciências de uma forma dinâmica e reflexiva. Há teorias da Cibernética que combinam com as teorias da Cartografia, dando origem à Cibercartografia, a qual se apresenta como paradigma diferenciado dos Sistemas de Informações Geográficos (SIG/GIS). Os produtos da Cibercartografia e do SIG oferecem possibilidades de desenvolvimento do raciocínio espacial nas aulas de Geografia. No entanto, eles permanecem ausentes na maioria das aulas por inúmeros motivos. Pretende-se, por este ensaio, compreender o significado da Cibercartografia no contexto do desenvolvimento da Cibernética e refletir sobre as causas da ausência deste tipo de Cartografia no ensino. Para refletir sobre estas questões, apresento os resultados parciais da pesquisa qualitativa realizada no ano de 2014 envolvendo entrevistas e observações das aulas de nove professores de Geografia do primeiro ano de oito escolas públicas do Distrito Federal. Os resultados nos revelaram a predominância dos mapas de papel. Tal prevalência do mapa analógico evidencia, ainda, as dificuldades dos professores no uso de imagens digitais nas aulas associadas à formação do professor. Embora alguns mapas digitais estejam presentes nas atividades em sala, o conhecimento da cartografia ainda é o clássico, tendo-se o mapa para ver, localizar, orientar um mapa para leitura. A interatividade com os mapas digitais inexiste, devido à limitação do conhecimento do professor e acesso aos novos mapas resultantes da evolução da Cartografia como ciência.
\end{abstract}

Palavras-chave: Cibercartografia. Ensino de Geografia. Cibernética.

\section{CYBERCARTOGRAPHY The Cartography paradigm still absent in Geography classes}

Abstract: The evolution of cybernetics occurs in different stages and generates new knowledge that influences the other sciences in a dynamic and reflexive way. There are theories of Cybernetics that combine with theories of Cartography, giving rise to the Cybercartography, which presents itself as a differentiated paradigm of the Geographic Information Systems (GIS/SIG). The products of Cybercartography and GIS offer possibilities in the development of the spatial reasoning in the classes of Geography. However, they were not present at most classes for numerous reasons. This essay intends to understand the meaning of Cybercartography in the context of the development of Cybernetics and to reflect on the causes of the absence of this type of Cartography in Geography classes of Basic Education. To reflect on these questions, I present the partial results of the qualitative research carried out in 2014 involving interviews and observations of the lessons of nine first year's teachers from eight High schools of the Federal District, DF. The results showed the predominance of paper maps in class. This prevalence of the analogic map also shows the teachers' difficulties in the use of digital images in classes associated with their academic training. Although some digital maps appeared in some classroom activities, the exercises of cartography are still basic, having the map to see, locate, guide - a map for reading. The interactivity with the digital maps does not exist, due to the limitation of the

\footnotetext{
${ }^{1}$ Doutora em Geografia na área de Cartografia Escolar. Professora da Carreira do Magistério Público da Secretaria de Estado de Educação do Distrito Federal - SEEDF. Integra o grupo de pesquisa - Ensino, Aprendizagem e Formação de Professores em Geografia da Universidade de Brasília - GEAF/UnB. E-mail: costa.vania0@gmail.com
} 


\section{REVISTA ELETRÔNICA \\ DA GRADUAÇÃO/PÓS-GRADUAÇÃO EM EDUCAÇÃO \\ UFG/REJ}

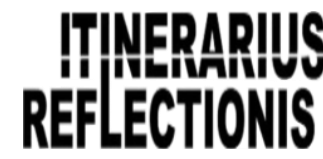

ISSN. 1807-9342

Volume 14, N. 2, 2018

professor's knowledge and access to the new maps resulting from the evolution of Cartography as a science.

Key words: Cybercartography. Teaching Geography. Cybernetics.

\section{INTRODUÇÃO}

A evolução da cibernética ocorre em diferentes etapas e geram novos conhecimentos que influenciam as outras ciências de uma forma dinâmica e reflexiva. Especificamente na Cartografia as teorias da Cibernética combinam com as teorias da Cartografia dando origem à Cibercartografia que se apresenta como paradigma diferenciado dos Sistemas de Informações Geográficos (SIG/GIS). Os produtos da Cibercartografia e do SIG oferecem possibilidades de desenvolvimento do raciocínio espacial nas aulas de Geografia. No entanto, eles permanecem ausentes da maioria das aulas de Geografia por inúmeros motivos. Pretende-se por este ensaio compreender o significado da cibercartografia no contexto do desenvolvimento da Cibernética e refletir sobre as causas da ausência deste tipo de Cartografia nas aulas de Geografia.

Compreender a existência de paradigmas na Cartografia é entender qual seria a unidade de ação da teoria científica que lhe dá suporte em determinado momento histórico. A ciência tem a base nas teorias científicas que mudam com o tempo. Os empiristas lógicos sustentam que as teorias coincidem umas as outras pelas reduções, porém preservando o que há de correto no seu núcleo central, que também estava presente na teoria anterior. Rosemberg (2013, p. 190) cita Kuhn como discordante dos empiristas lógicos sobre as mudanças de teorias científicas. Elas ocorrem pela substituição das leis teóricas por outras, em novas teorias ditas "paradigmas", que seriam as novas leis ou declarações científicas que conduziriam a ciência normal em direção ao progresso científico. O paradigma na obra kuhniana seria a unidade da ação do pensamento científico que inclui a apresentação, soluções, metodologia e equipamentos em um novo momento daquela ciência. Desta forma, refletimos: de que forma a cibercartografia apresenta estas novas leis teóricas, descritas por Kuhn, para ser considerada um paradigma na Cartografia? Iremos refletir esta questão no item a seguir.

\section{A CIBERCARTOGRAFIA}




\section{REVISTA ELETRÔNICA \\ DA GRADUAÇÃO/PÓS-GRADUAÇÃO EM EDUCAÇÃO \\ UFG/REJ}

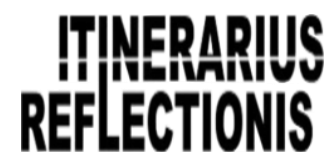

ISSN. 1807-9342

Volume 14, N. 2, 2018

A Cibercartografia foi apresentada em 1997 por Frazer Taylor, na Conferência Internacional da Associação Internacional de Cartografia, realizada em Estocolmo, Suécia. A maior parte dos projetos de Cibercartografia teve o seu desenvolvimento em dois grandes centros de pesquisa que é o Centro de Pesquisa de Geomática e Cartografia (GCRC, 2013), localizada em Carleton, Universidade de Ottawa, Canadá e o Centro de Investigação em Geografia e Geomática "Ing. J.L. Tamoyo" localizada na cidade do México. Em conjunto, estes dois centros desenvolveram o Atlas Cibercartográfico do Lago Chapala.

O novo termo Cibercartografia tem a ambição de mostrar a Cartografia como a combinação da arte e da ciência, permitindo o desenvolvimento do mapa com os seus componentes qualitativos e quantitativos de forma interativa. O Atlas Cibercartográfico trabalha com o conceito holístico na combinação de seus elementos e das suas formas em uma nova linguagem cartográfica para os espaços geográficos específicos. Isto porque o atlas cibercartográfico apresenta as seguintes características (GCRC, 2013):

- Multissensorial - oferece a possibilidade de ouvir, ver e tocar os mapas produzidos.

- Multimídia - oferece a possibilidade de uso de outros formatos de mídia utilizando a web 2.0.

- Interativo - usuários se transformam em criadores de mapas.

- Colaborativo - permite a aplicação para amplos repertórios de temas, muitos deles ainda não mapeados.

- Pesquisa - permite novas investigações e desenvolvimento de parcerias.

A Cibercartografia é defendida como o paradigma da Cartografia por Taylor (2005, p.2) por apresentar processos integrativos e evolutivos da Cibernética que incorpora elementos de outras teorias, redefine outras e indica novas idéias e conceitos da teoria e prática da Cartografia. O produto relevante da Cibercartografia é o Atlas Cibernético, definido por Taylor (2005) como produto social que oferece oportunidades de desenvolvimento cognitivo e social das pessoas que interagem com ele. $\mathrm{O}$ formato do Atlas Cibernético e os seus recursos multissensoriais, interativos, permite o compartilhamento de narrativas, discussão de temas controversos, manuseio de dados que mudam a relação do usuário com o mapa, transformando-o em criador do mapa. 


\section{REVISTA ELETRÔNICA \\ DA GRADUAÇÃO/PÓS-GRADUAÇÃO EM EDUCAÇÃO \\ UFG/REJ}

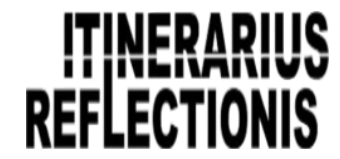

ISSN. 1807-9342

Volume 14, N. 2, 2018

A Cibercartografia tem o termo ciber se referindo não somente ao ciberespaço mas também à Cibernética e as teorias desenvolvidas na segunda ordem de sua evolução teórica. Este é um dos pontos relevantes de diferença dos produtos da Cibercartografia e dos mapas digitais produzidos pelos Sistemas de Informações Geográficas (SIG/GIS). Os mapas do SIG recebem influência das teorias desenvolvidas pela primeira ordem da Cibernética, com conceitos teóricos que permite apenas fazer o mapa para ler, ou seja, os mapas como produtos para a visualização espacial. Considero pertinente fazer um breve resumo sobre a evolução da cibernética para melhor diferenciar a Cibercartografia dos Sistemas de Informações Geográficas.

\section{A EVOLUÇÃO DA CIBERNÉTICA}

A Cibernética é uma palavra de origem grega Kubernêtes que significa piloto, ou no sentido figurado, a arte de dirigir os homens. A Cibernética surgiu como área científica em 1948 com a publicação de Norbert Wiener- Cibernética ou regulação e Comunicação no animal e na máquina. Esta ciência foi definida como a área científica que estuda o controle e a comunicação no animal e máquina. Desta forma a Cibernética é produto das discussões dos encontros interdisciplinares dos cientistas Nobert Wiener, John Von Neuman, Warren Mc McCulloch; Claude Shannon; Heinz von Foerster; W. Ross Ashby; Gregory Bateson e Margaret Mead nas Conferências de Macy, realizadas nos períodos de 1944 a 1953 nos Estados Unidos. (ASC, 2013).

Podemos dividir o desenvolvimento da Cibernética em quatro fases:

\section{Primeira fase da cibernética}

A primeira fase da Cibernética ocorreu no período de 1950 a 1960 com a aplicação da Teoria Geral dos Sistemas, TGS, inspirada nos trabalhos de Von Bertalanffy, biólogo austríaco que não concordava com a visão cartesiana do universo. Ele interpretava o organismo vivo como um sistema com as suas partes interligadas e interagindo dinamicamente. Na sua concepção teórica, Bertalanffy trabalhou com a ideia de que o organismo é um todo maior do que a soma das partes. Cada elemento ao ser reunido para constituir uma unidade funcional maior, desenvolveria qualidades que não se encontrariam em seus componentes isolados. Nesta fase a Teoria Geral dos Sistemas foi 


\section{REVISTA ELETRÔNICA \\ DA GRADUAÇÃO/PÓS-GRADUAÇÃO EM EDUCAÇÃO \\ UFG/REJ}

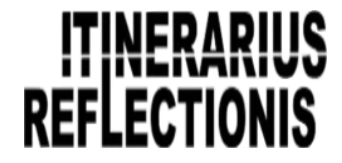

ISSN. 1807-9342

Volume 14, N. 2, 2018

desenvolvida em sistemas abertos e fechados, com o foco no arranjo do todo e nas interpelações orgânicas e estatísticas de suas partes.

Em outras palavras, nesta primeira fase, os estudos teóricos se concentraram nos comportamentos teleológicos dos mecanismos e automação dos comportamentos humanos. Wiener (1948, p.182) considerava a sociedade como uma unidade representada pelo sistema com intercomunicação entre os seus membros e o tamanho de unidade sistêmica era determinado pela efetiva transmissão de informação. Portanto, a Cibernética nasceu como ciência de controle da informação. Mas como controlar o comportamento humano? Wiener encontrou dificuldades para aplicar a Cibernética para as Ciências Sociais porque ele considerava que os dados da contextualização social eram influenciados pelos pesquisadores de alguma forma.

Avançando o estudo do funcionamento dos sistemas, notou-se que existiam ocasiões de instabilidade e a busca de novas formas de compreender o funcionamento destes em contextos sociais. O trabalho de Gregory Batenson e Ilya Prigogine permitiram avanços dos estudos com novas abordagens.

Gregory Batenson, biólogo e antropólogo inglês, trabalhou a visão sistêmica das relações sociais. Em seu livro Passos para uma Ecologia da Mente ( Steps to na Ecology of Mind) ele aplicou as teorias cibernéticas no campo da antropologia ecológica e o conceito da homeostase. Existem duas importantes contribuições de Batenson para esta primeira etapa da Cibernética. A primeira contribuição - Ele considerava o mundo como uma série de sistemas com os indivíduos, sociedades e ecossistemas juntos em dependência e susceptíveis às mudanças devido às múltiplas variáveis. A segunda contribuição - Foi a existência do grande Sistema, denominado Mente (Mind), formado pelos indivíduos, sociedade e ecossistema. Este grande sistema só poderia ser identificado e compreendido na sua totalidade. Neste contexto, o homem jamais seria capaz de controlar todo o sistema porque o sistema não é operado de uma forma linear, restava ao homem humildade para respeitar as limitações das explicações científicas do que ocorre internamente neste grande Sistema (GONÇALVES,2013).

Ilya Prigogine, químico russo, com os seus trabalhos sobre termodinâmica e os avanços nos modelos de caos cria a Teoria Geral dos Sistemas Fora do Estado de Equilíbrio conhecida como Lei do Caos. A Lei do Caos define que o mundo muda em 


\section{REVISTA ELETRÔNICA \\ DA GRADUAÇÃO/PÓS-GRADUAÇÃO EM EDUCAÇÃO \\ UFG/REJ}

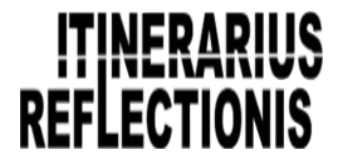

ISSN. 1807-9342

Volume 14, N. 2, 2018

direção ao futuro e os processos imutáveis ou irreversíveis são somente uma exceção ou erros localizados em uma escala temporal escolhida (GONÇALVES, 2013).

\section{Segunda fase da Cibernética}

Desde 1970, a Cibernética busca uma abordagem social adequada com o foco na autonomia do sistema e o papel do observador/pesquisador como parte da teoria social. O surgimento de teóricos com novas abordagens foi muito importantes nesta fase com destaque para Von Foster e Humberto Maturama (GONÇALVES, 2013).

A colaboração teórica de Von Foster com os temas da linguagem e cognição revelou possibilidades importantes nos estudos das ações dos indivíduos em uma sociedade, considerando a visão sistêmica. Von Foster era um cientista austríaco americano que conduziu pesquisas com ênfase na participação do pesquisador na produção da teoria social (GEYER ,1994).

Humberto Maturama também colaborou com a formulação da teoria social nesta segunda fase da Cibernética. Maturama propôs o pensamento sistêmico orientado pelo Construtivismo Radical. Em suas idéias ele considera que a realidade é uma construção válida mediante consenso, portanto existem várias realidades válidas em um sistema. (WINOGRAD e FLORES, 1986, p. 86).

$\mathrm{Na}$ área do conhecimento é importante citar os pesquisadores Erwin Laszló e Ernest Glaserfeld com suas importantes contribuições na construção do conhecimento. Erwin Laszló , filósofo e pianista húngaro foi um dos primeiros representantes da área da filosofia dos sistemas , utilizando a Teoria do Caos para identificar uma nova Teoria Geral da Evolução para um mundo melhor.(FIDEL ET AL., 2009) Ernest Glaserfeld, filósofo e professor de psicologia desenvolveu a epistemologia não convencional a respeito do problema do conhecimento e do ato de conhecer- Construtivismo Social. Suas teorias refletem a importância dos contextos políticos e sociais para moldar a ciência (RETAMOZO, 2013)

\section{Terceira fase da Cibernética}

Esta fase teve início na década de 80, a Cibernética refletiu o desenvolvimento das ciências da complexidade. Os estudos conceituais se concentraram no 


\section{REVISTA ELETRÔNICA \\ DA GRADUAÇÃO/PÓS-GRADUAÇÃO EM EDUCAÇÃO \\ UFG/REJ}

\section{ITWERAPUS \\ REFLECTONIS}

ISSN. 1807-9342

Volume 14, N. 2, 2018

desenvolvimento da vida artificial e da inteligência artificial com ênfase metodológica nas simulações multiagentes (GONÇALVES, 2013).

\section{Quarta fase da Cibernética}

A partir da década de 90 surge um paradigma na Cibernética - a Cibernética Quântica, com o suporte teórico da informação quântica incluindo os sistemas adaptativos complexos. (GONÇALVES, 2013)

\section{A RELAÇÃO DA CIBERCARTOGRAFIA COM A SEGUNDA FASE DA CIBERNÉTICA}

O atlas cibernético é considerado um artefato da segunda fase da cibernética. Estes atlas incluem software e hardware específicos. Eles são sistemas abertos de comunicação e representação do espaço geográfico e se desenvolve pelas interações contínuas dos diferentes atores sociais. A interação ocorre pela inserção de novas informações dos usuários responsáveis pela plataforma. Esta interação entre os usuários e os organizadores da plataforma caracteriza este sistema com o observador participativo, essencial em abordagem social, segundo Von Foster.

Outro aspecto do atlas cibernético, que o conecta com a segunda fase da cibernética, é a possibilidade das pessoas participarem dos sistemas com suas narrativas em contextos sociais e espaciais específicos, elementos para a construção do conhecimento social defendido pelo Construtivismo Social de Ernest Glaserfeld e do Construtivismo Radical de Humberto Maturama. A inclusão do relato individual em ambiente sistêmico é uma atividade inovadora na organização sistêmica e contribui para a construção histórica social do lugar do indivíduo. Neste contexto, o atlas cibercartográfico se mostra relevante no processo de comunicação construído em uma linguagem espacial que pode colaborar na organização do grupo social. (MARTINEZ e REYS, 2005)

Portanto, Taylor (2005) argumenta que a cibercartografia representa o novo paradigma da Cartografia porque ela representa um modelo a ser seguido por um grupo de cientistas que compartilham a mesma visão epistemológica da compreensão da realidade de forma sistêmica. O atlas cibercartográfico é desenvolvido por um grupo de pesquisadores e cientistas, GCRC e CIGC, que compartilham o mesmo conhecimento 


\section{REVISTA ELETRÔNICA \\ DA GRADUAÇÃO/PÓS-GRADUAÇÃO EM EDUCAÇÃO \\ UFG/REJ}

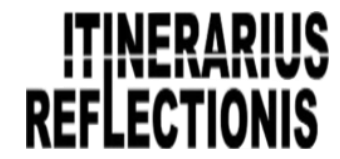

ISSN. 1807-9342

Volume 14, N. 2, 2018

científico, realizam experimentos e validam os seus resultados. Estes elementos representam a condição apropriada para colocar a cartografia como um paradigma, sob a ótica kuhniana.

A Cibercartografia surge em um campo de intersecção da Cartografia e da Cibernética que permite a compreensão do espaço social de uma forma holística e efetiva, trabalhando as interligações de seus elementos. Temos na Cibercartografia, a visão sistêmica dos atlas que conta com o observador participante - seja usuários ou organizadores do atlas em interação social que oferecem descrição de situações específicas que compõem parte da situação daquele grupo social.

\section{PODEMOS FALAR DE UMA CIBERCARTOGRAFIA NAS AULAS DE GEOGRAFIA?}

Primeiro iremos refletir a conexão da Cartografia e a Geografia. Observamos que mapear é uma função ancestral dos povos e acompanha a Geografia desde os primórdios. A comunicação visual através de desenhos ou representações de locais é mais fácil que a comunicação verbal e sempre existiu independente das tecnologias envolvidas. Esta comunicação visual envolve os mapas, as imagens espaciais percebidas na mente das pessoas e o mundo real. Nesse sentido, o mapa se apresenta como a linguagem espacial que auxilia a compreensão do espaço geográfico. Assim, a união entre as ciências geográfica e a cartográfica ao longo do tempo consolidou os mapas para expressar as mudanças espaciais.

As inovações da comunicação associada à tecnologia digital revelaram novas funções ao mapa além da localização. A partir da década de 60, por exemplo, os mapas recebem novas interpretações e preocupações sobre as informações que estes podem transmitir, reorientando todo o processo de produção do mapa como um meio de comunicação. Posteriormente, na década de 90 a utilização de programas de tratamento de dados espaciais que utiliza o Sistema de Informação Geográfica/SIG, em computadores individuais, trouxe os mapas digitais temáticos com informações relevantes de visualização dos dados geográficos. Em seguida, a cartografia multimídia inova com o mapa em 3D, som e imagem, que inclui a interação com os usuários dos mapas. Em consequência, o desenvolvimento da internet, do GPS e do sistema wireless 


\section{REVISTA ELETRÔNICA \\ DA GRADUAÇÃO/PÓS-GRADUAÇÃO EM EDUCAÇÃO \\ UFG/REJ}

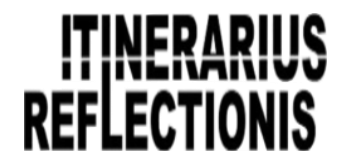

ISSN. 1807-9342

Volume 14, N. 2, 2018

incorporaram novas formas de ver e produzir os mapas. Morita (2015) caracteriza este processo como modo ubíquo de mapear, ou seja, aquele em que qualquer pessoa pode construir qualquer mapa, em qualquer lugar, em diferentes plataformas tecnológicas portáteis. O termo ubíquo é definido por Santaella (2013) como a conectividade entre pessoas e lugares via aparelhos eletrônicos, esta facilidade faz parte do dia a dia dos brasileiros, consumidores de mais de 198 milhões de smartphones do mundo (Estado de São Paulo, 2017).

Os celulares e a conexão com a internet transformam a condição contemporânea de nossa existência na forma ubíqua. Comunicamo-nos com as pessoas distantes como se elas estivessem ao nosso lado, consultamos a localização dos lugares no GPS dos celulares de uma forma natural como se a máquina sempre oferecesse a resposta correta. Interagimos com os aparelhos portáteis utilizando, produzindo e trocando informações. Muitas destas informações são espaciais a espera de leituras e interpretações que melhorem a qualidade da vida das pessoas. Este é o atual estágio tecnológico em que vivemos, onde a Cartografia ocupa um papel importante no processo de comunicação das informações espaciais nestes aparelhos portáteis. Este cenário de mundo com informações simultâneas, assíncronas e instantâneas acrescenta um novo papel à educação e, neste contexto, à escola, aos distintos campos disciplinares, em geral, e em particular à Geografia e à Cartografia. Assim a Cartografia, no âmbito da escolarização, oferece a oportunidade de desenvolvimento da compreensão e da realização da comunicação espacial na contemporaneidade.

A Cartografia é uma ciência que desenvolve técnicas, que podem ser utilizadas por outras ciências. Vista por alguns como uma ciência interdisciplinar, ela pode auxiliar no aprofundamento de questões que envolvem o espaço geográfico e aprofundar temas no ensino de Geografia. Tyner (2014) ressalta a diversidade dos mapas atuais como aqueles que não só representam a realidade de uma forma precisa, como também permitem a simulação de modelos futuros e comunicam as ideias de seus criadores. Nesta perspectiva o uso dos saberes cartográficos, nas aulas de Geografia, é importante, pois permite aos alunos a utilização de mapas para compreender onde, o porquê e como ocorrem os fenômenos espaciais a nível local e global. Os mapas atuais apresentam este potencial de organização, apresentação e comunicação de grande volume de informação espacial que estimula o exercício da análise, síntese e observação dos fenômenos naturais 


\section{REVISTA ELETRÔNICA \\ DA GRADUAÇÃO/PÓS-GRADUAÇÃO EM EDUCAÇÃO \\ UFG/REJ}

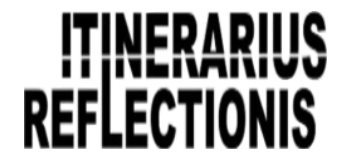

ISSN. 1807-9342

Volume 14, N. 2, 2018

e humanos importantes para a formação do cidadão em um mundo conectado (TAYLOR, 1991). Tal situação, entretanto, evidencia uma problemática acerca do tipo de Cartografia ensinada nas escolas: as aulas de Geografia acompanharam a evolução da Cartografia? Podemos encontrar a cibercartografia nas aulas de Geografia? Para refletir sobre estas questões apresento os resultados parciais da pesquisa qualitativa realizada no ano de 2014 com nove professores de geografia do Ensino Médio. Detalhes desta pesquisa serão descritas a seguir.

\section{METODOLOGIA}

Oito escolas públicas foram selecionadas em diferentes localidades do DF e nove professores (P1, P2, P3, P4, P5, P6,P7, P8 e P9) de Geografia do primeiro ano do Ensino Médio foram entrevistados e tiveram suas aulas observadas. O objetivo geral da pesquisa foi o de compreender as práticas cartográficas dos professores de Geografia nas escolas públicas do Ensino Médio do Distrito Federal. Neste artigo, apresentaremos um resultado parcial decorrente do questionário sociocultural, entrevistas e observação em sala a respeito do uso da tecnologia em sala de aula. Tais análise nos permitem a reflexão sobre o uso de mapas produtos da geotecnologia e a existência da cibercartografia nas aulas de Geografia.

As entrevistas apresentaram os seguintes tópicos que especificam o uso de tecnologias nas práticas cartográficas das aulas de geografia.

1. Perfil do entrevistado como idade, anos de magistério e formação acadêmica

2. Você sabe o que é geotecnologia? Descreva.

3. Você sabe o que é Google Earth? Descreva.

4. A escola oferece condições para o uso de tecnologias nas aulas de Geografia?

As observações em sala de aula contaram com as anotações, em diário de campo, relacionadas ao ambiente, com o uso de recursos, a interação professor/aluno, a dinâmica particular de cada professor ao trabalhar o conteúdo da aula, assim como com a organização da escola ao proporcionar recursos e suporte pedagógico ao professor de geografia. Alguns professores permitiram a observação de mais de duas aulas e dois professores permitiram a observação participante, com o desenvolvimento de atividades cartográficas. A professora 1 teve três aulas observadas; o professor 2 teve quatro aulas 


\section{REVISTA ELETRÔNICA \\ DA GRADUAÇÃO/PÓS-GRADUAÇÃO EM EDUCAÇÃO \\ UFG/REJ}

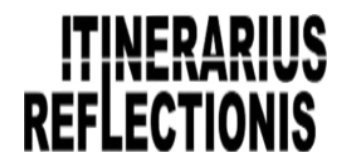

ISSN. 1807-9342

Volume 14, N. 2, 2018

observadas; o professor 3 teve duas aulas observadas; o professor 4 teve quatro aulas observadas; a professora 5 teve duas aulas observadas; o professor 6 teve duas observadas; o professor 7 teve oito aulas observadas; o professor 8 teve duas aulas obervadas e a professora 9 teve cinco aulas observadas no total de 32 aulas observadas durante o ano de 2014. As aulas eram de 50 minutos cada.

Fizemos a opção pela pesquisa qualitativa porque este tipo de pesquisa permite uma melhor aproximação dos sujeitos da ação pesquisada, permite observá-los, descrevelos e compreender as suas ações. A obtenção dos dados da pesquisa qualitativa ocorre com os seus sujeitos situados em seus cenários naturais, captados pelo olhar particular do pesquisador que exercerá importante papel na interpretação de dados (DENZIN e LINCOLN, 2006).

As informações das entrevistas e das observações em sala de aula foram categorizadas e exploradas segundo a concepção da análise de conteúdo. Essa se apresenta como "um conjunto de técnicas sistemáticas e objetivas de investigação dos conteúdos presentes nas mensagens" (BARDIN, 1977, p. 38). Seu objetivo é a decodificação das mensagens para evidenciar indicadores que permitam inferir acerca de outra realidade que não aquela diretamente expressa na mensagem.

\section{RESULTADOS}

O perfil dos professores nos permitiu concluir que todos são experientes e com idade acima de 40 anos, com exceção da professora P5, recém formada e de contrato temporário. A maior parte dos professores se formou nas décadas de 1980 e 1990, em faculdades privadas, no curso Licenciatura em Geografia. Apenas um professor, P2, fez o curso de Estudos Sociais, em instituição privada. Eles complementaram os seus estudos em cursos de pós-graduação nos anos 2000. Para muitos, as atividades docentes iniciaram no ano seguinte após a formatura, sendo que alguns permaneceram na mesma escola da educação básica. A figura 1, a seguir, apresenta as siglas LP= Licenciatura Plena; PCN= Parâmetros Curriculares Nacionais; $\mathrm{CM}=$ Currículo em Movimento da Educação Básica que sistematiza essas informações.

As diretrizes e leis educacionais, como DCNEM (BRASILc, 1998), PCN (BRASILb, 2000) e LDB (BRASILa, 2014), responsáveis pelo redirecionamento da 


\section{REVISTA ELETRÔNICA \\ DA GRADUAÇÃO/PÓS-GRADUAÇÃO EM EDUCAÇÃO UFG/REJ}

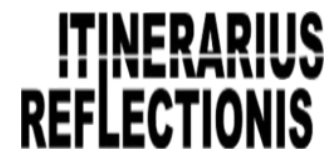

ISSN. 1807-9342

Volume 14, N. 2, 2018

aprendizagem em uma perspectiva mais humanista, que, por conseguinte, conferiram à cartografia o papel de linguagem, aconteceram após o período de graduação da maioria desses professores, ou seja, após 1996. Infere-se, assim, que eles não tiveram, em sua formação acadêmica, seja em instituições públicas, seja em privadas, as noções de trabalho pedagógico que considerassem a cartografia como linguagem (BRASILd,2016). Nesse sentido, a formação docente anterior a esse período (1996) insere-se na perspectiva da concepção da cartografia clássica, que privilegia a matemática do espaço e designa ao mapa a função de artefato artístico cultural, distante também da concepção da cartografia analítica da cibercartografia que requer eficiente internet na escola.

O período de formação dos professores também revela a dificuldade na conceituação de geotecnologia pelo docente, que apareceu de forma menos elaborada, conforme mostra o Quadro 1. NR significa item não respondido pelo professor, ou seja, aquele que não soube definir o que era geotecnologia e Google Earth. Outras respostas

Figura 1. Formação Acadêmica dos professores entrevistados.

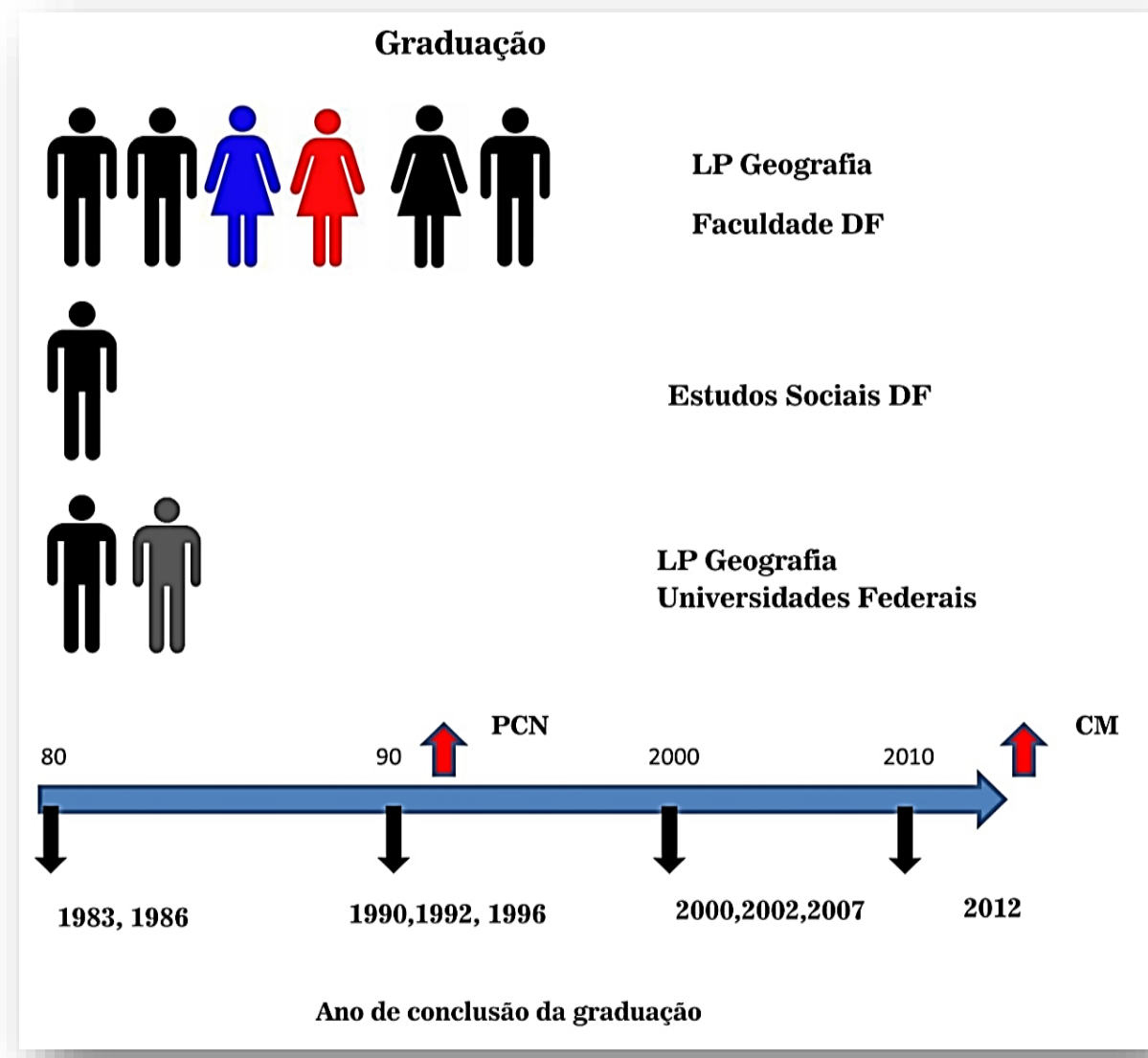

Fonte: Souza, 2016 


\section{REVISTA ELETRÔNICA \\ DA GRADUAÇÃO/PÓS-GRADUAÇÃO EM EDUCAÇÃO \\ UFG/REJ}

\section{ruspowus REFLECTONIS}

ISSN. 1807-9342

Volume 14, N. 2, 2018

indicam que o professor apenas descreveu o termo como a junção de geografia mais tecnologias, alguns associam ao GPS (Global Positioning System), um sistema de posicionamento por satélite que fornece a um aparelho receptor móvel a sua posição ao satélite. Outros simplificam o sensoriamento remoto à palavra satélite. Notamos que o programa Google Earth é muito citado nas entrevistas. Compreendemos aqui a definição de geotecnologias como sendo um conjunto de tecnologias, entre elas, Sistema de Informação Geográfica, geoprocessamento, cartografia digital, sensoriamento remoto, Sistema de Posicionamento Global, GPS e a Cibercartografia. Esses sistemas permitem uma visão sistêmica do evento geográfico e envolvem desde a coleta, o processamento, a análise e visualização de informações espaciais. Essas informações estruturam-se em banco de dados georreferenciados que permitem análise detalhada. (ROSA, 2005). As geotecnologias são importantes para o exercício do geógrafo. Nas escolas, elas oferecem potencialidades de visualização, mas necessitam do professor treinado para usar os vários programas disponíveis na internet. Notamos que o professor que utiliza em casa o Google Earth, assim o faz na escola. Desta forma, ele utiliza os conhecimentos obtidos pela sua prática no cotidiano.

Quadro 1: Concepção de geotecnologia e Google Earth.

\begin{tabular}{|l|l|l|}
\hline Escolas/Professores & \multicolumn{1}{|c|}{ Definição de Geotecnologia } & \multicolumn{1}{|c|}{ Definição de Google Earth } \\
\hline E1P1 & $\begin{array}{l}\text { Uso de várias tecnologias } \\
\text { voltadas para a Geografia }\end{array}$ & $\begin{array}{l}\text { Modo de visualização geográfica } \\
\text { para imagens em várias escalas }\end{array}$ \\
\hline E2P2 & $\begin{array}{l}\text { Tecnologia aplicada ao } \\
\text { desenvolvimento da Cartografia }\end{array}$ & $\begin{array}{l}\text { Programas de fotos e } \\
\text { localizações }\end{array}$ \\
\hline E3P3 & NR & $\begin{array}{l}\text { Programa de computador sobre } \\
\text { o globo terrestre em 3 D }\end{array}$ \\
\hline E4P4 & $\begin{array}{l}\text { Aplicação de tecnologia à } \\
\text { Geografia }\end{array}$ & Sistema de mapeamento \\
\hline E5P5 & NR & NR \\
\hline E6P6 & Aparelho GPS e satélite & NR \\
\hline E7P7 & $\begin{array}{l}\text { Tecnologia associada ao SIG e } \\
\text { Geografia }\end{array}$ & NR \\
\hline E8P8 & NR & NR \\
\hline E8P9 & $\begin{array}{l}\text { Uso de tecnologia no ensino de } \\
\text { Geografia }\end{array}$ & Muita coisa, mapas e imagens \\
\hline \hline
\end{tabular}

Fonte: Souza, 2016 


\section{REVISTA ELETRÔNICA \\ DA GRADUAÇÃO/PÓS-GRADUAÇÃO EM EDUCAÇÃO \\ UFG/REJ}

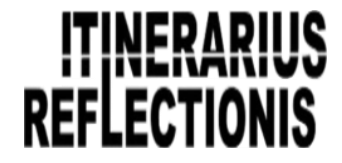

ISSN. 1807-9342

Volume 14, N. 2, 2018

Podemos encontrar a cibercartografia nas aulas de Geografia? Nas aulas de geografia, nos momentos de discussão teórica do espaço dinâmico, do fluxo de mercadorias, observou-se a predominância dos mapas de papel. Tal prevalência do papel evidencia, ainda, as dificuldades dos professores no uso de imagens digitais nas aulas. Pode-se justificar tal situação pela formação desses professores, que não os preparou para os diferentes usos dos mapas. Se por um lado as escolas foram equipadas por computadores com incentivos dos programas federal e distrital de inclusão digital. Esses equiparam as escolas da rede pública de ensino com computadores, internet e oferta de cursos de preparação dos professores, no uso das tecnologias de informação e comunicação. Por outro lado, a presença de equipamentos não foi suficiente para inovações nas aulas. A respeito dessas iniciativas governamentais, algumas análises, entre as quais se destaca a de Ferreira (2009), identificam que poucas práticas digitais dos professores acontecem nas escolas. Nesse sentido, um dos problemas apontados em sua pesquisa refere-se à falta de um professor responsável pela sala de informática. Assim, na ausência desse profissional, a opção recai sobre deixá-las fechadas. Por outro lado, os professores utilizam a sua experiência pessoal com alguns programas de mapeamento e os utilizam nas aulas, mesmo com lentidão da internet, como, por exemplo, o Google Maps, em aparelhos celulares e computadores pessoais. Mesmo assim, a cibercartografia ainda permanece como palavra estranha às práticas cartográficas nas escolas e os professores desconhecem este termo. Isto ocorre, pois o mapa ainda é utilizado na função clássica de localização,longe de uma análise da cibercartografia que amplia esta função do mapa.

Pela entrevista notamos que a cartografia está presente na vida dos professores. A experiência e vivência com os mapas influenciam muito os professores de geografia e alguns não dissociam a cartografia da geografia. Sete professores se lembraram da sua primeira experiência com os mapas no passado e a maioria utiliza os mapas, seja na forma analógica, seja na forma digital, em casa e nas aulas. Embora os mapas digitais estejam presentes nas atividades do professor, o conhecimento da cartografia ainda é o clássico, tem-se o mapa para ver, localizar, orientar, o mapa para leitura. A interatividade com os mapas digitais inexiste, talvez pela limitação de conhecer as ferramentas de vários programas geoespaciais, dentre eles o programa Google Earth, que oferece também restrições de informações que devem ser esclarecidas para os usuários (CAZETA, 2011). 


\section{REVISTA ELETRÔNICA \\ DA GRADUAÇÃO/PÓS-GRADUAÇÃO EM EDUCAÇÃO \\ UFG/REJ}

\section{CONSIDERAÇÕES FINAIS}

Podemos associar essa limitação do uso de mapas com a formação dos professores. A maioria dos professores graduou-se 26 anos atrás e, portanto, não tiveram a formação acadêmica da cartografia sequer como linguagem, uso de mapas digitais e conhecimento dos produtos da Cibercartografia. A concepção presente, nas aulas, é da cartografia clássica, do mapa na função de artefato artístico cultural, aquele utilizado para leitura apenas. Eles conhecem os mapas digitais da cartografia moderna, mas não fizeram cursos para utilizá-los de uma forma mais ampla e analítica. Os professores ainda possuem essa lacuna de conhecimento acerca das diferentes funções que o mapa assume na era contemporânea, conforme pesquisa de Fernandez e Buchroithner (2014): mapa como artefato científico cultural, linguagem espacial, comunicação visual, mapa modelo e instrumento de visualização.

Enfatizamos a necessidade dos cursos de formação continuada para discutir as diferentes formas de uso e construção de mapas, a evolução da Cartografia e as possibilidades didáticas da Cibercartografia. Ações complementares para o funcionamento efetivo das salas de informática e melhoria da internet nas escolas públicas possibilitariam o início do uso da Cibercartografia nas aulas de Geografia.

\section{REFERÊNCIAS}

ASC -American Society for Cybernetics . Disponível em <http://www.asccybernetics.org/foundations/history/MacySummary.htm> 1 de dezembro de 2013.

BARDIN, L. Análise de conteúdo. Lisboa: Edição 70, 1977

BRASILa. Brasil - Lei no 9394/1996 - Estabelece as diretrizes e bases da educação nacional., 2014. URL. Disponível em: $<$ http://www.planalto.gov.br/ccivil 03/leis/19394.htm>. Acesso em: 25 nov. 2014.

BRASILb. Parâmetros curriculares nacionais: orientações curriculares para o ensino médio: ciências humanas e suas tecnologias, 2000. URL. Disponível em:

$<$ http://portal.mec.gov.br $>$. Acesso em 25 nov. 2014.

BRASILc. Brasil - Ministério da Educação - Parecer CNE/CEB nº 3 /junho de1998. Estabelece as diretrizes curriculares nacionais gerais para o ensino médio, 1998. URL. Disponível em: <http://portal. mec.gov.br>. Acesso em: 25 nov. 2014. 


\section{REVISTA ELETRÔNICA \\ DA GRADUAÇÃO/PÓS-GRADUAÇÃO EM EDUCAÇÃO \\ UFG/REJ}

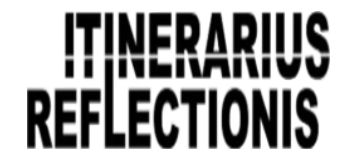

ISSN. 1807-9342

Volume 14, N. 2, 2018

BRASILd Parecer CNE/CES 492/2001. Diretrizes curriculares nacionais dos cursos de geografia. Disponível

em: $<$ http://portal.mec.gov.br/cne/arquivos/pdf/CES0492.pdf $>$. Acesso em: 15 jun. 2016.

FERNANDEZ, P. ; BUCHROITHNER,M. Paradigms in Cartography, an epistemological review of the 20th and 21th centuries. New York: Springer. 2014.

CAZETA,V. Educação visual do espaço e o Google Earth. In ALMEIDA,R.(org.) Novos rumos da cartografia escolar:currículo, linguagem e tecnología. São Paulo: Ed. Contexto. 2011.

DENZIN,N. ; LINCOLN,Y. O planejamento da pesquisa qualitativa. Teorias e abordagens. P 15-41Porto Alegre: Editora Artmed. 2006.

ESTADO DE SÃO PAULO Jornal, Reportagem do dia 19/4/2017. O Brasil chega a 168 milhões de smartphphones em uso. Disponível em

$<$ http://link.estadao.com.br/noticias/gadget,brasil-chega-a-168-milhoes-de-

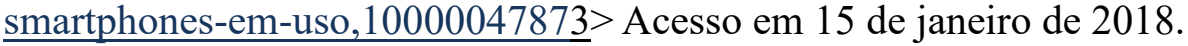

FERREIRA, M. Introdução digital de professores da Secretaria de Educação do Distrito Federal: um estudo sobre a formação docente . Dissertação.2009. Faculdade de Educação, UnB, Brasília, 2009.

FIDEL MARTINEZ, ORTIZ ,Eloy, GONZALEZ Ania, BRITO Humberto Antecedentes, iniciadores y fundamentos de los estudios de la complejidad, Quórum Académico, vol. 6, núm. 1, enero-junio, pp. 79-120, Universidad del Zulia, Venezuela 2009.

GCRC, Geomatic and Cartography Research Center. Disponível em

< https://gcrc.carleton.ca/confluence/display/GCRCWEB/Overview> Acesso em 1 de dezembro de 2013.

GEYER, F. The Challenge of sociocybernetics, Simposium VI Challenges to Sociological Knowledege, $13^{\text {th }}$ World Congress of Sociology, Bielefeld, 18-24 jul. Disponível em < ftp://ftp.vub.ac.be/> Acesso em 1 de dezembro de 2013.

GONÇALVES Carlos P., 2013, As Quatro Fases da Cibernética e a Ciência da Tomada de Decisão. Disponível em < https://www.academia.edu/4820997/> Acesso em 1 de dezembro de 2013.

MARTINEZ, Elvia, REYS, Maria Del Carmen, Technology and Culture in Cybercartography, chapter 6, In TAYLOR, Fraser, Cybercartography:Theory and Practice. Elsevier B. V. Amsterdam, The Netherlands, 2005.

MORITA, Takashi. A Working Conceptual Framework for Ubiquitous Mapping. Proceedings of the 22 nd International Cartographic Conference. 2005. 


\section{REVISTA ELETRÔNICA \\ DA GRADUAÇÃO/PÓS-GRADUAÇÃO EM EDUCAÇÃO \\ UFG/REJ}

\section{ITHEPRAPUIS REFLECTONIS}

ISSN. 1807-9342

Volume 14, N. 2, 2018

RETAMOZO, Martín, Constructivismo: Epistemología y Metodología en las ciencias sociales, Diponível em

$\langle$ http://docencia.izt.uam.mx/egt/Cursos/MetodologiaMaestria/Retamozo.pdf $\rangle$ Acesso em 1 de dezembro de 2013.

ROSA, Roberto, Geotecnologia na Geografia Aplicada, Revista do Departamento de Geografia, 16, p 81-90, 2005.

ROSENBERG, Alex, Introdução à filosofia da Ciência, 2 ed, São Paulo, Edições Loyola, 2013.

SANTAELLA, Maria Lúcia B. , Comunicação Ubíqua, Paulus, 2013.

SOUZA, V.L.C.A., A cartografia como linguagem nas aulas de Geografia: Desafios dos professores do Ensino Médio das escolas públicas do Distrito Federal, Tese de Doutorado, Pós Graduação Geografia, Universidade de Brasília, 2016.

TAYLOR, Fraser, Cybercartography: Theory and Practice. Elsevier B. V. Amsterdam, The Netherlands,2005.

TAYLOR,D.R.F. A conceptual basis for cartography: new directions for the information era. Cartoghaphica, v. 28, n. 4, p.1-8, Toronto, 1991.

TYNER,J. The world of map and interpretation for the 21st century. New York: The Guildford Press. 2014. 